\title{
The Ontogeny of Pulmonary Defenses: Alveolar Macrophage Function in Neonatal and Juvenile Rhesus Monkeys
}

\author{
GEOFFREY KURLAND, ANTHONY T. W. CHEUNG, MICHAEL E. MILLER, SUSAN A. AYIN, \\ MAUNG M. CHO,' AND ELIZABETH W. FORD \\ Department of Pediatrics, University of California Davis, School of Medicine; and California Primate Research \\ Center, University of California, Davis, California 95616
}

\begin{abstract}
Using the technique of bronchoalveolar lavage, we isolated alveolar macrophages (AM) from the lower respiratory tract of newborn (1-4 days of age), infant (6-10 days of age), juvenile (3-6 months of age), and adult rhesus monkeys. The AM thus obtained were assayed in vitro to determine their chemotactic, phagocytic, and candidicidal capabilities. The predominant $(\geq 89 \%)$ cell type in bronchoalveolar lavage effluent in all ages was the AM. Chemotaxis, phagocytosis, and killing of Candida albicans were markedly impaired in neonatal AM as compared with those from infants, juveniles, and adults. AM chemotactic activity achieved normal adult values by 6 days of age. Phagocytosis, and to a lesser extent candidicidal activity, were significantly improved in 6-day-old animals, but adult levels were still not achieved even by 6 months of age. (Pediatr Res 23: 293-297, 1988)
\end{abstract}

\section{Abbreviations}

AM, alveolar macrophage

BAL, bronchoalveolar lavage

LRT, lower respiratory tract

PMN, polymorphonuclear leukocyte

LPS, lipopolysaccharide

CPRC, California Primate Research Center

PBS, phosphate-buffered saline

The lower respiratory tract has a complex defense system to maintain its normally sterile state (1). Components of this defense system include physical barriers to prevent the entry of microorganisms to the distal airways; a mucociliary blanket that can trap and eliminate particulate material; humoral factors such as lactoferrin, immunoglobulins, and complement; and cellular components. The major cellular component involved in the defense of the lower respiratory tract is the AM, which is responsible for the recognition, ingestion, and killing of invading bacterial and fungal pathogens $(2,3)$. Additionally, macrophages are capable of generating materials including leukotrienes (4), which can act as chemoattractants to peripheral neutrophils (PMN), which also participate in the pulmonary inflammatory response (5)

The neonate is particularly susceptible to bacterial infections

Received September 9, 1986; accepted November 16, 1987.

Correspondence Geoffrey Kurland, M.D. Department of Pediatrics, UC Davis Medical Center, 4301 X Street, Sacramento, CA 95817.

Supported in part by USPH-NICHD base Grant RR-00169 and by the California Research Medical Education Fund of the American Lung Association of California

${ }^{1}$ World Health Organization Fellow, 1985. of the lower respiratory tract, with a significant resultant morbidity and/or mortality (6). Previous workers have documented deficiencies in aspects of AM function in neonatal rabbits (710 ). Nonhuman primates offer a highly relevant model for the study of pulmonary defenses as many aspects of their immunologic defenses are similar to those of humans $(11,12)$. Despite this advantage, there are few studies of the function of pulmonary defenses in infant nonhuman primates $(13,14)$, and little delineation of the normal development of pulmonary defenses in this animal model.

We have examined the functional characteristics of AM in rhesus monkeys and have found that in vitro chemotaxis, yeast phagocytosis, and intracellular candidicidal activity are deficient in AM obtained by BAL of newborn animals. These functions are normal or nearly normal by 6 days of age. There are, however, important differences in the rapidity of development of these functions in AM from infant and juvenile nonhuman primates.

\section{MATERIALS AND METHODS}

The techniques involved in BAL, cell determination and chemotactic, phagocytic, and candidicidal activities have been described in detail previously (15) and are briefly summarized.

Animals. Rhesus monkeys (Macaca mulatta) at the CPRC were used in the study. Six newborns 1-4 days of age, eight infants 6-10 days of age, 15 juveniles 3-6 months of age, and 25 adults more than the age of 4 yr comprised the study groups. All animals were housed in individual cages except newborns and infants, which were kept in cages with their mothers. All animals were healthy, without cough, weight loss, or anorexia; veterinary staff at the CPRC were consulted if any questions as to the animals' health were raised. All personnel and animals at the CPRC are routinely screened for active mycobacterial disease with yearly skin testing.

$B A L$. Animals were fasted for at least $6 \mathrm{~h}$ and anesthetized with intramuscular ketamine hydrochloride $(10-15 \mathrm{mg} / \mathrm{kg})$. The glottis was visualized using a pediatric laryngoscope and local anesthesia was achieved with a small amount of $2 \%$ Cetacaine spray in older animals. A double-lumen balloon-tipped catheter (American Edwards, Santa Ana, CA), 4-French in newborns and neonates, 5-French in juveniles, and 7- or 10-French in adults, was passed through the vocal cords and wedged in a lower lobe bronchus. Previous study in our laboratory has demonstrated that the catheter enters the right lower lobe bronchus in more than $95 \%$ of such manipulations.

The balloon was inflated and 6 aliquots of sterile Dulbecco's PBS, $1-3 \mathrm{ml} / \mathrm{kg}$, were infused and withdrawn. The balloon was deflated and the catheter removed.

Handling of lavage fluid. The recovered lavage fluid was centrifuged at room temperature for $10 \mathrm{~min}$ at $500 \times \mathrm{g}$. The super- 
natant was stored at $-70^{\circ} \mathrm{C}$. The cell pellet was resuspended in a small volume of PBS and the cells were counted using a hemocytometer. Trypan blue exclusion was used as a test of cell viability. The cell suspension was smeared on a slide and stained with methyl violet stain and a differential cell count performed.

Functional studies. Cells obtained by BAL were predominantly $(\geq 89 \%)$ alveolar macrophages. Alveolar macrophages were resuspended in McCoy's 5a medium (modified) with L-glutamine and $10 \%$ fetal bovine serum (GIBCO, Grand Island, NY) at a concentration of $1 \times 10^{6} / \mathrm{ml}$.

Chemotaxis. A total of $0.2 \mathrm{ml}$ of the alveolar macrophage suspension was placed in the upper portion of a blind well chemotactic chamber (Millipore, Bedford MA) over an $8-\mu \mathrm{m}$ pore-sized cellulose ester filter (Nucleopore, Pleasanton, CA). A solution of $40 \mathrm{mg}$ Escherichia coli LPS (Sigma, St. Louis, MO) in $0.4 \mathrm{ml}$ of pooled normal adult monkey plasma was diluted with $1.6 \mathrm{ml}$ of McCoy's media; $0.2 \mathrm{ml}$ of this solution, containing $4.0 \mathrm{mg}$ of LPS was placed in the lower well of each chamber. For negative controls, $0.2 \mathrm{ml}$ of McCoy's media without LPS was placed in the lower chamber well. Chambers were incubated at $37^{\circ} \mathrm{C}$ for $3 \mathrm{~h}$, the filters removed and stained with modified hematoxylin-Wright stain, and viewed on a microscope. The number of alveolar macrophages per high power field $(100 \times$, oil immersion) migrating to the lower surface of the filter was counted. Ten fields were counted on each filter and averaged. Each macrophage suspension was assayed in triplicate.

Phagocytic and candidal killing assays. Phagocytic and killing capacities of AM were evaluated with a modified fluorochrome assay $(16,17)$. Two drops of the alveolar macrophage suspension were placed on a glass cover slip. Two drops of a suspension 48to 72 -h old culture of Candida albicans blastospores $\left(2 \times 10^{6} /\right.$ $\mathrm{ml} \mathrm{McCoy's} \mathrm{5a} \mathrm{modified} \mathrm{medium} \mathrm{with} 5 \%$ rhesus monkey serum) were added to each cover slip and incubated for $4 \mathrm{~h}$ at $37^{\circ} \mathrm{C}$. Cover slips were then rinsed to remove nonphagocytized blastospores, stained for $60 \mathrm{~s}$ with $1.6 \times 10^{-4} \mathrm{M}$ acridine orange, and mounted on a glass slide.

Slides were viewed under fluorescence microscopy and at least
100 macrophages examined and scored for ingestion and killing of Candida particles. Live intracellular Candida blastospores fluoresce pale green, while killed blastospores fluoresce copper red (17). Phagocytosis was calculated as the percentage of cells with three or more ingested particles. Cellular killing was calculated as the percent of ingested Candida blastospores killed. All cell suspensions were studied in triplicate.

Verification of acridine orange technique. To verify the accuracy of the acridine orange technique we compared AM phagocytosis and candidacidal activity in parallel, using adult rhesus AMs and a modified acridine orange or Giemsa staining technique $(18,19)$.

AMs were obtained from three adult monkeys and were diluted to $1 \times 10^{6} / \mathrm{ml}$ in McCoy's 5a media supplemented with $10 \%$ fetal calf serum. Aliquots of $100 \mu \mathrm{l}$ of the cell suspension were placed on titertek glass slides and preincubated for $20 \mathrm{~min}$ at $37^{\circ}$ $\mathrm{C}$ in air- $5 \% \mathrm{CO}_{2}$. A total of $25 \mu \mathrm{l}$ of fresh monkey serum were added, followed by $50 \mu \mathrm{l}$ of a $C$. albicans suspension $\left(1 \times 10^{6} /\right.$ $\mathrm{ml}$ of McCoy's 5a media supplemented with $5 \%$ rhesus monkey serum). After gently mixing, the slides were incubated at $37^{\circ} \mathrm{C}$ for $3.75 \mathrm{~h}$ in air- $5 \% \mathrm{CO}_{2}$. One group of slides were rinsed with $0.9 \%$ sterile saline, rapidly air dried, fixed with absolute methanol for $1 \mathrm{~min}$, and stained with a 1:50 aqueous dilution of Giemsa stain (Harleco, Gibbstown, NJ) for 20 min. For the remaining group of slides, acridine orange staining was carried out as described above.

Slides were viewed on a microscope and cells counted for uptake of $C$. albicans. On Giemsa stained slides, intracellular organisms were classified as viable (dark blue staining) or nonviable (clear, light blue, or blue with a pink staining nuclear body). Two hundred cells were scored for phagocytosis and candidacidal activity, with one or more ingested particles being counted as positive for phagocytosis. Acridine orange staining was scored as noted above, except that phagocytosis was scored as cells with one or more intracellular organism. Cells were studied by both techniques in triplicate. The mean values for triplicate results were compared.

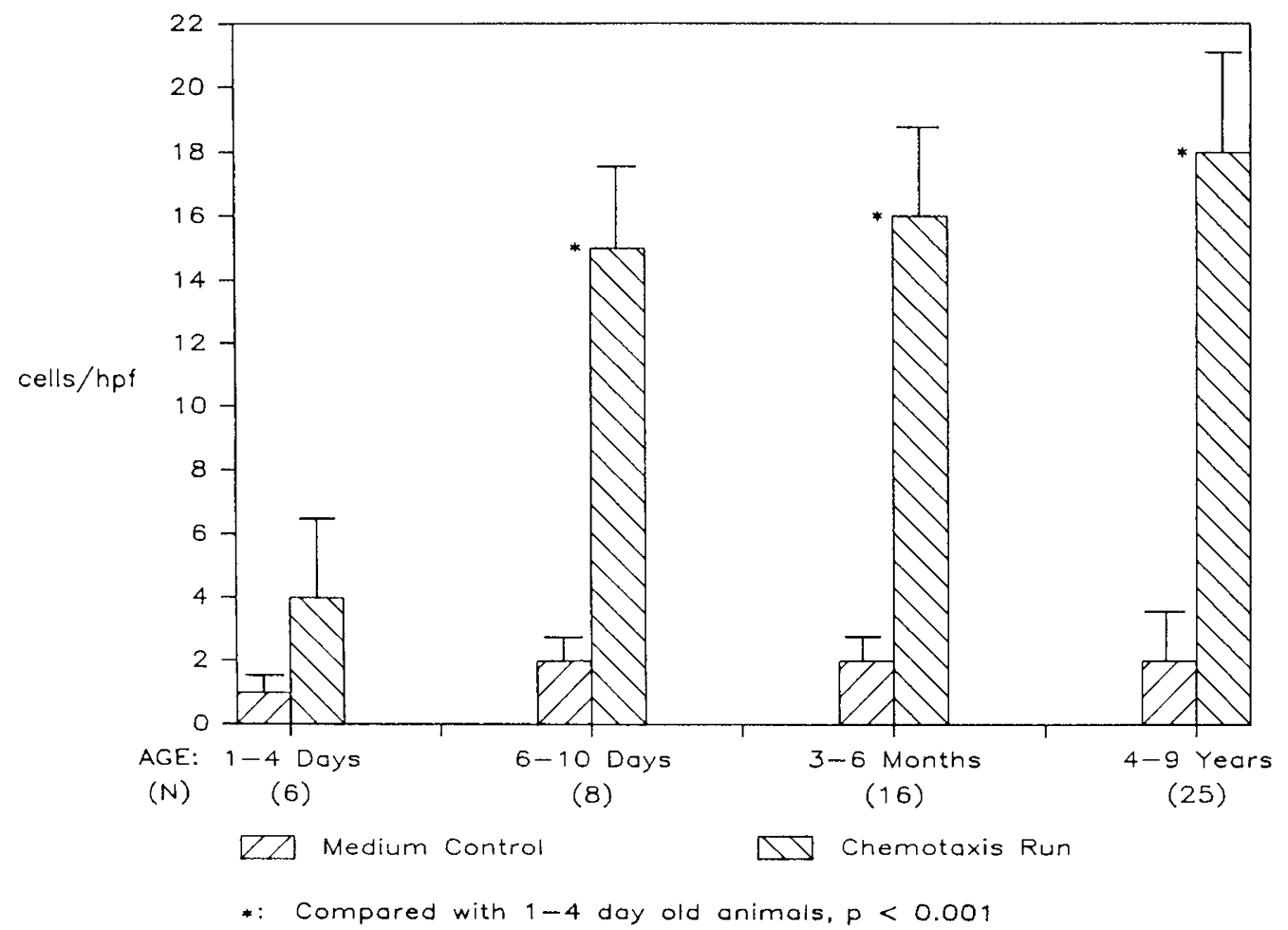

Fig. 1. AM chemotaxis. Hatched bar height depicts mean number of cells migrating to the lower side of the millipore filter. Vertical line is SD. For each group of animals, value for media control run is depicted to left and the run with LPS in the lower well as chemoattractant on right. 
Statistical analysis. Student's $t$ test for unpaired samples was used to compare the results of chemotactic, phagocytic, and candidicidal studies.

\section{RESULTS}

Monkeys of all age groups tolerated bronchoalveolar lavage without untoward effects.

AM chemotaxis. AM obtained in the initial lavage from neonatal (1-4 day old) animals had minimal chemotactic activity to endotoxin-activated plasma (Fig. 1). The number of macrophages migrating to the lower side of the millipore filter was $4 \pm$ 2.5 per high power field. Macrophages obtained from all other groups demonstrated normal chemotaxis, with values significantly higher than those of the neonates. Adults had $18 \pm 3.1$ ( $p$ $<0.001)$, juveniles $16 \pm 2.9(p<0.001)$, and infants $6-10$ days of age $15 \pm 2.6(p<0.001)$ cells per high power field migrating through the filter in response to endotoxin-activated plasma.

AM phagocytosis. AM from newborn (1-4 day old) animals demonstrated poor phagocytosis (Fig. 2). Cells ingesting three or more $C$. albicans particles were $12 \pm 5 \%$ of the total number of cells counted. When compared with these values, the phagocytic index (percentage of cells ingesting three or more particles) of alveolar macrophages from older animals was significantly higher. For infants $6-10$ days of age, the value was $56 \pm 4 \%(p$ $<0.001)$, for juveniles it was $66 \pm 8 \%(p<0.001)$, and for adults it was $75 \pm 15 \%(p<0.001)$. When AM from animals between the ages of 6 days and 6 months of age were compared with adult animals, the phagocytic index was also significantly decreased ( $p$ $<0.01$ ).

AM intracellular candidicidal activity. AM obtained from newborn monkeys showed poor intracellular candidicidal activity by the acridine orange assay (Fig. 3). The killing index (percent of ingested C. albicans particles killed) in these cells was $17 \pm 2 \%$. Cells from 6- to 10-day-old infants exhibited a killing index of $80 \pm 5 \%(p<0.001)$, whereas juveniles had a killing index of $82 \pm 10 \%(p<0.001)$. The killing index of AM from adult animals, $86 \pm 13 \%$, was also significantly different from newborns $(p<0.001)$.

Comparison of acridine orange and Giemsa staining methods. Results of three parallel studies comparing acridine orange and Giemsa staining to score AM for phagocytosis and candidicidal activity are shown in Table 1. As can be seen, there was good agreement between both techniques, with a maximum of $10 \%$ discrepancy in phagocytosis scoring noted.

\section{DISCUSSION}

LRT infections are a major source of morbidity and mortality in infants and children (6). The vulnerability of the newborn LRT to invasion by pathogens suggests deficiencies in one or more of the defense mechanisms that adequately protect the LRT of the adult (20).

A primary cellular defense of the LRT is the AM, which is capable of ingesting and killing bacterial and fungal pathogens $(1,2)$. Our results document in vitro functional defects in AM obtained from newborn primates. Specifically, AM from neonatal animals have minimal chemotactic, phagocytic, and candidicidal activities.

Other investigators have demonstrated specific deficiencies of AM function and pulmonary defenses in newborn animals. Kradin et al. (21) demonstrated a reduction of AM surface opsonic receptor function in rats less than $5 \mathrm{wk}$ of age. Ultrastructural examination of newborn AM revealed large numbers of multilammelar bodies, which were not seen in adult AM. Flow cytometry studies of AM stained for heat-aggregated rabbit IgG suggested that the density of Fc receptors is decreased in newborn AM as compared with adult cells.

Sherman et al. (7) showed decreased in vitro intrapulmonary killing of Staphylococcus aureus by 1-day-old rabbits as compared to 7-and 14-day-old controls. Further, they suggested that Staphylococci were ingested and killed less effectively by AM in 1-day-old rabbits. Using the technique of isolated lung lavage, Sieger (22) obtained somewhat different results in rabbits. He

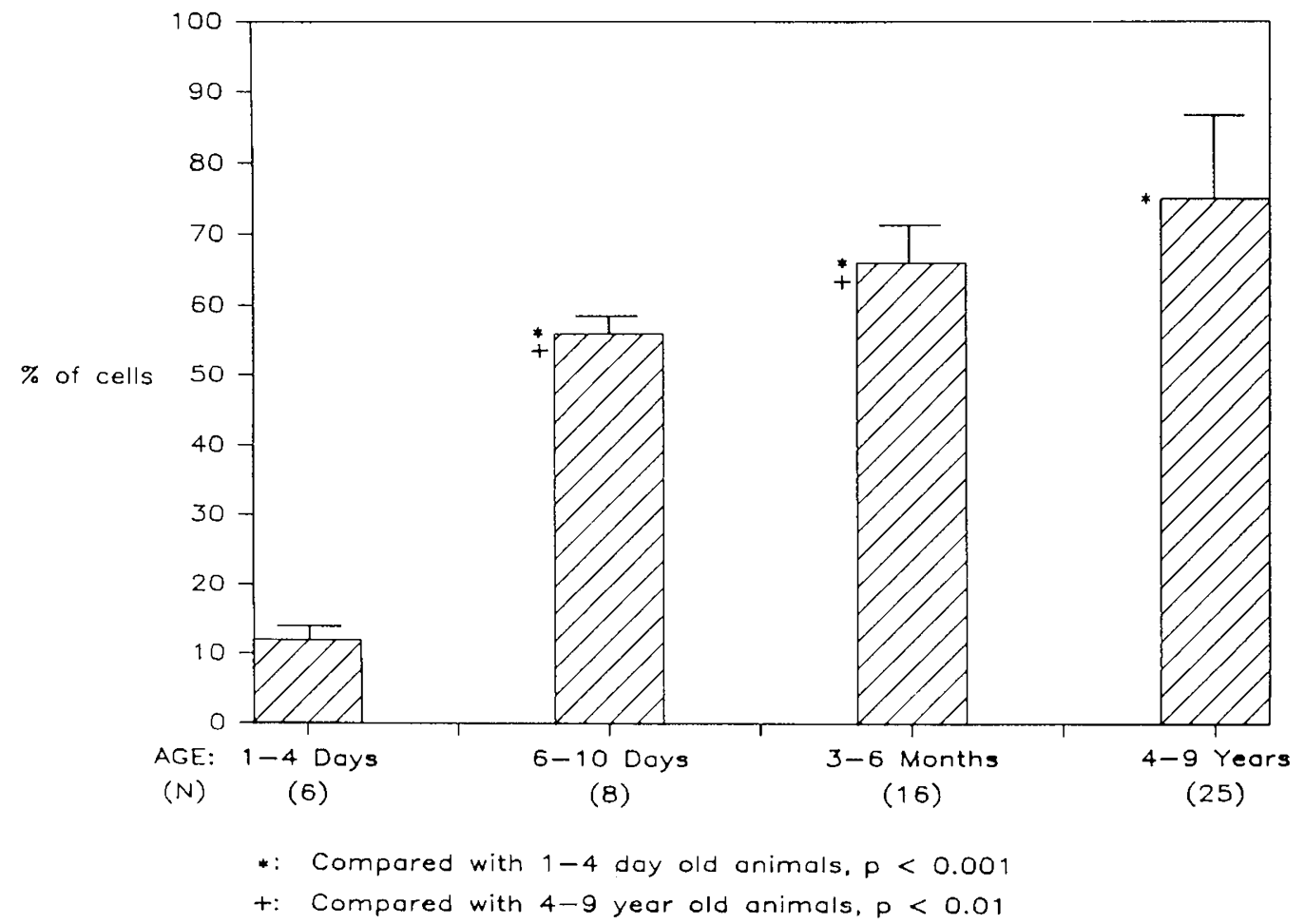

Fig. 2. AM phagocytosis. Hatched bar height depicts mean percent of cells ingesting three or more yeast particles. Vertical line is SD. Note that while AM from animals age 6 days or more had increased phagocytosis compared with newborn $(p<0.001)$, the phagocytic function of AM from 6-day to 6-month-old animals remained significantly less than AM from adult animals $(p<0.01)$. 


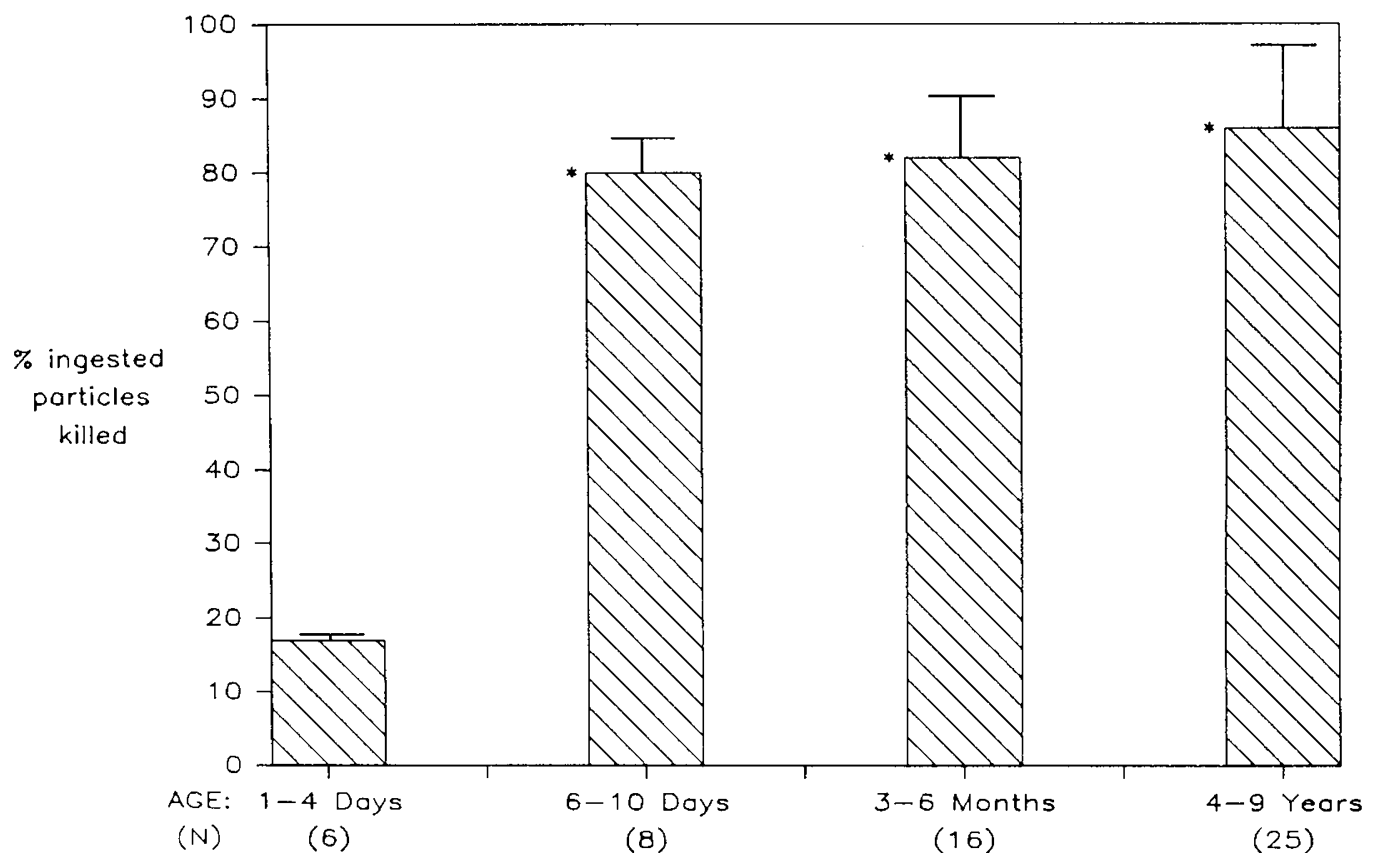

*: Compared with $1-4$ day old animals. $p<0.001$

Fig. 3. AM intracellular candidicidal activity. Hatched bar depicts the mean percent of ingested Candida blastopores killed by AM from different age animals (assayed by acridine orange fluorescence). Vertical line is the SD. Note that AM from all animals older than age 6 days had significantly increased candidicidal activity compared with $\mathrm{AM}$ from newborn animals $(p<0.001)$.

Table 1. Comparison of AM phagocytosis and candidicidal activity as determined by acridine orange $(A O)$ and Giemsa staining technique

\begin{tabular}{ccc}
\hline $\begin{array}{c}\text { Monkey } \\
\text { ID no. }\end{array}$ & $\begin{array}{c}\text { Phagocytosis (\%) } \\
\text { Giemsa/AO }\end{array}$ & $\begin{array}{c}\text { Candidicidal } \\
\text { activity (\%) } \\
\text { Giemsa/AO }\end{array}$ \\
\hline 20254 & $27 / 21$ & $20 / 22$ \\
16701 & $34 / 24$ & $31 / 30$ \\
17718 & $40 / 46$ & $32 / 33$ \\
\hline
\end{tabular}

found an increasing number of $\mathrm{AM} / \mathrm{g}$ wet weight of lung in the prenatal period, with a rapid rise to adult levels by the $3 \mathrm{rd}$ postnatal day. Normal bactericidal activity against Pseudomonas aeruginosa and $S$. aureus was found in AM from newborn rabbits. Methodologic differences may explain the contrasting findings between these two studies. Sieger (22) used an AM to bacterium ratio of approximately 5:1 and an agitated incubation system, which may have facilitated the interaction of AM with bacteria.

Sherman (8) also noted impaired phagocytic activity of lung AM after exposure of neonatal rabbits to a hyperoxic environment. More recently, Ganz et al. (9) reported deficiencies of the microbicidal cationic protein MCP-1 (23) with AM from 1-, 7-, and 21-day-old rabbits, with the deficiency being most marked in the youngest animals. Bellanti and coworkers $(10,24)$ demonstrated postnatal developmental changes in rabbit AM which correlated with developing functional competency of the cell.

Studies in ring-tailed rhesus monkeys demonstrated an increase in absolute numbers of alveolar macrophages within the first two postnatal days in term animals (13). Jacobs et al. (14) also showed that phagocytosis of Staphylococci and group B Streptococci by AM from infant rhesus monkeys (mean age 3.8 wk) was equivalent to that of adult control AM after $15 \mathrm{~min}$ of incubation. After prolonged incubation ( $45 \mathrm{~min}$ ), however, adult AM had greater bactericidal activity. The effect of the preincubation of AM with the immunoregulating synthetic glycopeptide aminobutyryl muramyl dipeptide (25) resulted in the enhancement of the bactericidal activity in the infant AM, whereas adult AM were not significantly improved in their bactericidal activity by this pretreatment.

Data from our laboratory have demonstrated that peripheral blood PMN from healthy neonatal rhesus monkeys are impaired in their ability to move in a directed fashion toward a chemoattractant (Cheung ATW, Miller ME, unpublished observations). These findings are similar to those in human neonates reported by Miller (26). Our findings of diminished chemotaxis in newborn monkey AM are consistent with abnormal chemotactic function of other phagocytic cells in neonates.

The use of acridine orange as a vital stain to distinguish viable from nonviable $C$. albicans has certain potential pitfalls in interpretation (27). The most important of these is the possibility that the orange fluorescence of the yeast particles merely reflects fusion of lysosomal contents with the phagosome, rather than yeast death. This confounding possibility would be more likely with preincubation of macrophages with the acridine orange followed by yeast phagocytosis $(28,29)$. Our technique, however, is based on brief postphagocytic staining with acridine orange, rather than relying on the preincubation of macrophages with the lysosomotrope acridine orange. Schuit (17) as well as Smith and Rommel (30) have used a staining technique similar to ours and confirmed it with other methods to differentiate phagocytosis from killing. Mor and Goren (31) have recently studied the use of acridine orange as a stain for intracellular candidicidal activity in mouse peritoneal macrophages and concluded that staining most likely signifies killed or severely injured yeast particles. Further, we have performed companion assays with acridine orange and methylene blue staining (19) using neutrophils from humans and primates, with comparable results for both phagocytosis and intracellular killing. Herein, the fluorochrome assay was confirmed using adult rhesus AM with the Giemsa staining technique of Lehrer and coworkers $(18,19)$. Therefore, we believe it is reasonable to interpret our results using differential staining by acridine orange as a true reflection of candidicidal activity. 
A potential difficulty with the microscopic scoring of phagocytosis is the differentiation of those Candida particles that have been ingested by macrophages from those that are merely adherent to the macrophage plasma membrane. Our laboratory has used yeast phagocytosis as a standard method for nearly two decades (32). On numerous occasions, we have verified our results obtained by light microscopy by simultaneously performed election microscopy. Under the experimental conditions outlined herein, the data are highly correlated, with apparent ingestion by light microscopy being confirmed by electron microscopy.

The candidicidal activity of adult rhesus AM in our study exceeds that reported in other experimental animals such as rabbits $(33,34)$ and guinea pigs $(35)$. We have compared the acridine orange method with the Giemsa staining method using adult rhesus AM and believe that our results are accurate. When these two techniques were compared, as reported in Table 1, the percentages reported for phagocytosis and candidicidal activity are lower than those we obtained during our experimental studies of newborn, infant, juvenile, and adult AM. We believe that these differences may be explained by several important factors, including the age of $C$. albicans cultures used in the experimental $(48-72 \mathrm{~h})$ and the comparison $(24 \mathrm{~h})$ studies, as well as differences in $C$. albicans concentrations used in both cases. Despite these variabilities in techniques, we believe that the major difference seen in candidicidal activity of newborn and adult rhesus AM tested by the fluorochrome assay is indicative of true functional impairment in newborn AM.

The timing of the appearance of AM that can function at adult levels in the rhesus monkey is similar to the development of other aspects of immunologic defenses. We have previously demonstrated that neutrophil influx into the perturbed lung is absent in newborn monkeys, but appears at an intermediate level in animals between 6 days and 8 months of age $(15,36)$. Peripheral blood neutrophil chemotaxis is also markedly deficient in newborn monkeys, achieving normal levels by 6 days of age. Of particular interest is the observation that the development of this aspect of neutrophil function is dependent on the postnatal rather than the gestational age; neutrophils from preterm animals show normal chemotaxis by the 6th postnatal day, as do neutrophils from full-term animals. Further study of the ontogeny of AM function, as well as those factors that may retard or speed its development, should prove useful in our understanding and control of neonatal infections involving the LRT.

Acknowledgments. Karen A. Staggs and Becky L. Glasgow aided in the preparation of the manuscript. Andrea J. Bettendorfs provided skills in computer graphics.

\section{REFERENCES}

1. Green GM 1970 In defense of the lung. Am Rev Respir Dis 102:691-703

2. Green GM, Kas EH 1964 The role of the alveolar macrophage in the clearance of bacteria from the lung. J Exp Med 119:167-176

3. Murphy S, Florman AL 1983 Lung defenses against infection: a clinical correlation. Pediatrics $72: 1-15$

4. Martin TR, Merritt TL, Albert RK, Henderson WR 1984 Leukotriene B $_{4}$ production by the human alveolar macrophage. A potential mechanism for amplifying inflammation in the lung. Am Rev Respir Dis 129:106-111

5. Wood WB 1952 Studies on the cellular immunology of acute bacterial infections. Harvey Lect 47:72-98

6. Avery ME, Fletcher BD, Williams RB 1981 Infections. In: Avery ME, Fletcher BD, Williams RB (eds) The Lung and its Disorders in the Newborn Infant. WB Saunders, Philadelphia, pp 203-221

7. Sherman M, Goldstein E, Lippert W, and Wennberg R 1977 Neonatal lung defense mechanisms: a study of the alveolar macrophage system in neonatal rabbits. Am Rev Respir Dis 116:433-440

8. Sherman MP 1985 Hyperoxia and phagocytic defenses of the newborn lung. Clin Res 33:143A(abstr)

9. Ganz T, Sherman MP, Selsted ME, Lehrer RI 1985 Alveolar macrophages of newborn rabbits are deficient in microbicidal cationic proteins, MCP-1 and MCP-2. Am Rev Respir Dis 132:901-904

10. Bellanti JA, Nerurkar LS, Zeligs BJ 1979 Host defenses in the fetus and neonate: studies of the alveolar macrophage during maturation. Pediatrics 64:726-739

11. Scully C 1981 Comparable phagocytic activity of rhesus monkey and human blood polymorphonuclear leukocytes. Lab Anim 15:323-325

12. Voormolen-Kalova M, van den Berg, Radly J 1974 Immunoglobulin levels as related to age in non human primates in captivity. II. Rhesus monkeys. J Med Primatol 13:343-350

13. Jacobs RF, Wilson CB, Palmer S, Springmeyer SC, Henderson WR, Glover DM, Kessler DL, Murphy JH, Hughes JP, Van Belle G, Chi EY, Hodson WA 1985 Factors related to the appearance of alveolar macrophages in the developing lungs. Am Rev Respir Dis 131:548-553

14. Jacobs RF, Wilson CB, Smith AL, Haas JE 1983 Age-dependent effects of aminobutyryl muramyl dipeptide on alveolar macrophage function in ithant and adult Macaca monkeys. Am Rev Respir Dis 128:862-867

15. Cheung ATW, Kurland G, Miller ME, Ford EW, Ayin SA, Walsh EM 1986 Host defense deficiency in newborn non human primate lungs. J Med Primatol 15:37-47

16. Cheung ATW, Liu IKM, Walsh EM, Miller ME 1985 Phagocytic and killing capacities of uterine-derived polymorphonuclear leukocytes from mares resistent and susceptible to chronic endometritis. Am J Vet Res 46:19381940

17. Schuit KE 1979 Phagocytosis and intracellular killing of pathogenic yeasts by human monocytes and neutrophils. Infect Immun 24:932-938

18. Oseas R, Lehrer RI 1978 A micromethod for measuring neutrophil candidacidal activity in neonates. Pediatr Res 12:828-829

19. Lehrer RI 1970 Measurement of candidicidal activity of specific leukocyte types in mixed cell populations. Infect Immun 2:42-47

20. Wilson CB 1986 Immunologic basis for increased susceptibility of the neonate to infection. J Pediatr 108:1-12

21. Kradin RL, McCarthy KM, Schneeberger EE 1986 Opsonic receptor function is reduced on the surface of newborn alveolar macrophages. Am Rev Respir Dis 133:238-244

22. Sieger L 1978 Pulmonary alveolar macrophages in pre- and post-natal rabbits. J Reticuloendothelial Soc 23:389-395

23. Patterson-Delafield J, Martinez RJ, Lehrer RI 1980 Microbicidal cationic proteins in rabbit alveolar macrophages: a potential host defense mechanism. Infect Immun 30:180-192

24. Zeligs BJ, Nerurkar LS, Bellanti JA, Zeligs JD 1977 Maturation of the rabbit alveolar macrophage during animal development. I. Perinatal influx, into alveoli and ultrastructural differentiation. Pediatr Res 11:197-208

25. Chedid L, Audibert F, Johnson AG 1978 Biological activities of muramyl dipeptide, a synthetic glycopeptide analogous to bacterial immunoregulating agents. Prog Allergy 25:63-105

26. Miller ME 1978 Phagocytic cells. In: Host Defenses in the Human Neonate. Grune and Stratton, New York, pp 59-71

27. Goren MB, Swendsen CL, Henson J 1980 Factors modifying the fusion of phagosomes and lysosomes: art, fact, and artifact. In: van Furth R (ed) Mononuclear Phagocytes. Martinus Nijhoff, The Hague, pp 999-1038

28. de Duve C, de Barsy T, Poole B, Trouet A, Tukens P, van Hoof F 1974 Lysosomotropic agents. Biochem Pharmacol 23:2495-2531

29. Hart PD, Young MR 1975 Interference with normal phagosome-lysosome fusion in macrophages, using ingested yeast cells and suramin. Nature 256:47-49

30. Smith DL, Rommel F 1977 A rapid micro-method for the simultaneous determination of phagocytic-microbicidal activity of human peripheral blood leukocytes in vitro. J Immunol Methods 17:241-247

31. Mor N, Goren MB 1987 Discrepancy in assessment of phagosome-lysosome fusion with two lysosomal markers in murine macrophages infected with Candida albicans. Infect Immun 55:1663-1667

32. Miller ME 1969 Phagocytosis in the newborn infant: humoral and cellular factors. J Pediatr 74:255-259

33. Arai T, Mikami Y, Yokoyama K 1977 Phagocytosis of Candida albicans by rabbit alveolar macrophages and guinea pig neutrophils. Sabouradia 15:171177

34. Lehrer RI, Ferrari LG, Patterson-Delafield J, Sorrell T 1980 Fungicidal activity of rabbit alveolar and peritoneal macrophages against Candida albicans. Infect Immun 28:1001-1008

35. Voisin C, Aerts C, Tonnel A-B, Ramon P 1977 Etude in vitro de l'activite bactericide (Staphylococcus aureus) et fongicide (Candida albicans) des macrophages alveolaires de cobaye en presence de diproprionate de beclomethasone. Nouv Presse Med 6:1326-1328

36. Kurland G, Cheung ATW, Miller ME 1985 Lack of neutrophil (PMN) movement into the neonatal primate lung. Clin Res 33:147A(abstr) 